\title{
Optical Control, Diagnostic and Power Supply System for a Solid State Induction Modulator
}

\author{
R. Saethre \\ Bechtel Nevada Corporation
}

H. Kirbie, B. Hickman, B. Lee, C. Ollis

LLNL

This paper was prepared for submittal to the 11th IEEE International Pulsed Power Conference

Baltimore, Maryland

June 29-July 2, 1997

June 4, 1997

This is a preprint of a paper intended for publication in a journal or proceedings. Since changes may be made before publication, this preprint is made available with the understanding that it will not be cited or reproduced without the permission of the author. 


\section{DISCLAIMER}

This document was prepared as an account of work sponsored by an agency of the United States Government. Neither the United States Government nor the University of California nor any of their employees, makes any warranty, express or implied, or assumes any legal liability or responsibility for the accuracy, completeness, or usefulness of any information, apparatus, product, or process

disclosed, or represents that its use would not infringe privately owned rights. Reference herein to any specific commercial product, process, or service by trade name, trademark, manufacturer, or otherwise, does not necessarily constitute or imply its endorsement, recommendation, or favoring by the United States Government or the University of California. The views and opinions of authors expressed herein do not necessarily state or reflect those of the United States Government or the University of California, and shall not be used for advertising or product endorsement purposes. 


\title{
OPTICAL CONTROL, DIAGNOSTIC AND POWER SUPPLY SYSTEM FOR A SOLID STATE INDUCTION MODULATOR
}

\author{
R. Saethre \\ Bechtel Nevada, Las Vegas, NV 89193 \\ H. Kirbie, B. Hickman, B. Lee, C. Ollis \\ Lawrence Livermore National Laboratory, Livermore, CA 94558
}

\begin{abstract}
A new high speed optical control, diagnostic and power supply system has been developed for a solid state induction modulator. The modulator consists of a large array of field effect transistors (FETs) that switch a high-voltage pulse across a tape-wound magnetic core. The FETs within the modulator are mounted on numerous circuit boards that are stacked in series for high-voltage operation. The new optical system overcomes the issue of voltage isolation by supplying each circuit board with optically coupled control power and high bandwidth signal information. An optical fiber is used to transmit laser light to a custom photovoltaic cell that provides dc power to the on-board control circuits. Optical fiber technology is again used to convey a pulse that contains detailed analog features to the FET gate controls. Diagnostic data and status information are also obtained from each board by similar optical methods.
\end{abstract}

\section{INTRODUCTION}

Three subsystems are being developed to produce an all optical modulator that uses optical fibers to achieve analog control, low-voltage power supply, and diagnostics. The modulator consists of a large array of field effect transistors (FETs) that switch a high-voltage pulse across a tape-wound magnetic core [1]. The FETs within the modulator are mounted on numerous circuit boards that are stacked in series for high-voltage operation. The new optical subsystems overcome the issue of voltage isolation and unwanted coupling capacitance by supplying each circuit board with optically coupled control power and high bandwidth signal information. Analog control of FETs can be used to regulate the modulator voltage and correct for pulse distortion due to loading of the modulator. An optically isolated power system that utilizes laser energy to power the electronic systems on each circuit board is used to eliminate ground loops and reduce coupling capacitances. A resistor in series with the source lead of the FETs is used for over-current protection and its small value makes it useful as a current viewing resistor (CVR). Converting the CVR signal to light supplies isolated diagnostic data and status information to the control system.

\section{ANALOG OPTICAL CONTROL}

The solid state induction modulator requires an analog control subsystem to operate each FET in the linear region, which allows active voltage regulation of the modulator output pulse. This ability can be used to correct for pulse distortions due to loading of the modulator. The subsystem fans out a $10 \mathrm{MHz}$ control signal to many receivers on voltage isolated printed circuit boards. Measurements of the switch modulator revealed that the series arrangement of the FET switch boards requires the control signals be timed so that the skew between any two receivers is less than 1 nanosecond. Timing skews greater than 1 nanosecond can place the entire switching voltage across one FET, causing it to exceed its voltage handling capabilities.

Conversion to a digital format for transmission over optical fiber was chosen for this application because the digital format is stable and less sensitive to changes in received optical power and thermal variations. Converting the digital signal to analog on the switch board was 
accomplished with a digital-to-analog-converter (DAC). To reproduce the input signal, the Nyquist Sampling Theorem requires a sampling rate of at least two times the highest analog frequency. Therefore, a $10 \mathrm{MHz}$ input signal is reproduced without aliasing if sampled at a rate of more than $20 \mathrm{MHz}$.

Creating the digital bit stream was accomplished by converting the analog signal to digital with an analog-to-digital-converter (ADC). A vertical cavity surface emitting laser (VCSEL) array fiber optic transceiver [2], [3] link was used to transmit the parallel digital signals over optical fibers to a $400 \mathrm{MHz}$ DAC. See Figure 1. The VCSEL link transmits 10 channels in parallel at up to 400 Mbps per channel for a total bit rate of 4 Gbps.

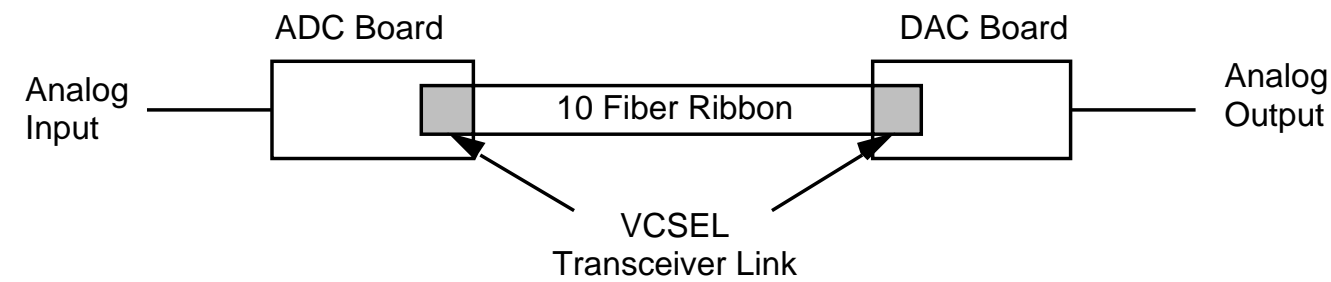

Fig. 1 -- Schematic of Analog Control Subsystem

Testing was performed with sampling rates of $1 \mathrm{MHz}$ to $400 \mathrm{MHz}$. The DAC used was a 6 bit converter, two channels of the VCSEL link were used for transmitting the CLOCK and NOT-CLOCK signal and the other two channels were not used. Conversion of the analog signal to digital proved to be the more difficult problem. The system had oscillations with a period of $2 \mathrm{~ns}$ at sampling frequencies $\left(f_{s}\right)$ over $100 \mathrm{MHz}$. Due to improperly connected ground planes on the ADC board, we used ferrite beads to isolate the noisy digital ground plane from the clean analog ground. Sampling rates were reduced to $300 \mathrm{MHz}$ for reliable performance.

A $15 \mathrm{MHz}$ sine wave input signal and the output of the DAC are shown in Figure 2 for a sampling rate of $300 \mathrm{MHz}$. The resolution of this DAC is given by the vertical number of bits and the sampling rate. This DAC has a vertical resolution of 6 bits or 64 discrete levels. Dividing the output range into 64 levels gives $16 \mathrm{mV}$ per level. A sampling rate of $300 \mathrm{MHz}$ is a sample point every $3.3 \mathrm{~ns}$. which gives 20 samples in one cycle of the $15 \mathrm{MHz}$ sine wave. Looking closely at the waveforms in Figure 2, discrete levels or steps can be seen in both the input and the output waveforms. Filtering the output of DAC with a low pass filter or increasing the sampling rate will smooth out the steps.

Input/ Output with fs $=300 \mathrm{MHz}$

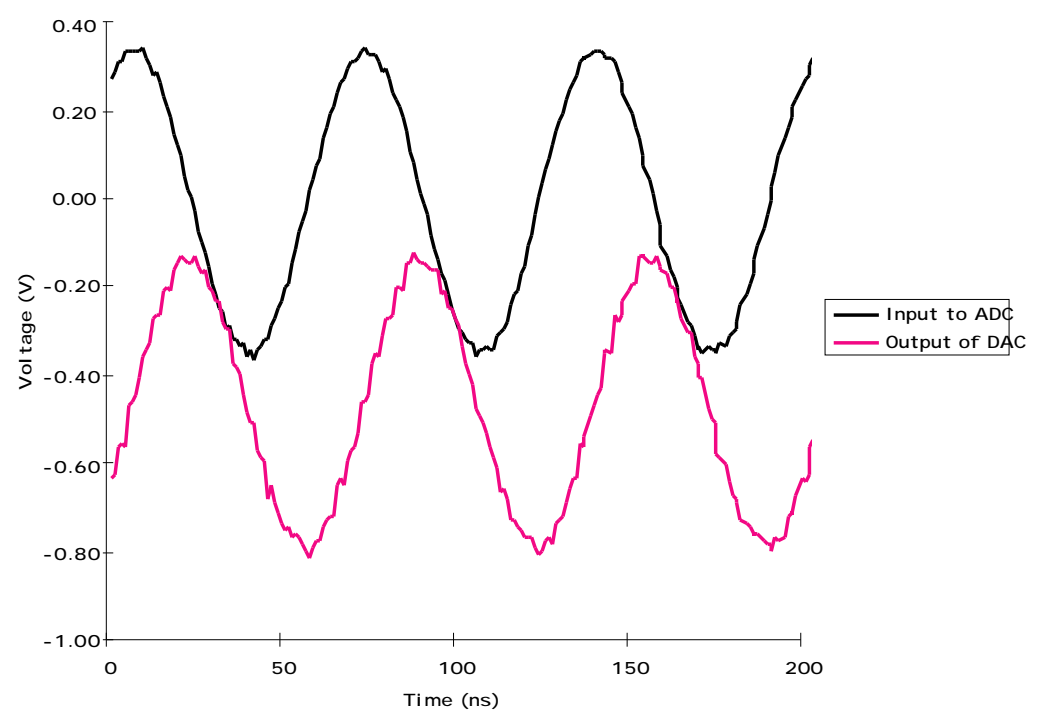

Fig. 2 -- Plot of DAC Input and Output 
The DAC output is ideally 0 volts to -1 volts with discrete steps at every $15.6 \mathrm{mV}$, corresponding to the binary input incrementing by one least significant bit (LSB). After compensating for an offset error of $80 \mathrm{mV}$, the gain error (difference in slopes of the transfer functions) was measured at $1.4 \%$, well below the specified value of $6.5 \%$ from the manufacturer. The gain error can be compensated by adjusting the reference current of the DAC. The offset error can be compensated by adjusting the bias level on the reference input on the DAC. Only the dynamic errors remain, which include the differential non-linearity error (DNL) and integral nonlinearity error (INL). DNL is a measure of the difference between an actual step height and the ideal value of 1 LSB. INL is the accumulated DNL.

Measurements of analog bandwidth, risetime, falltime, spurious free dynamic range (SFDR), signal to noise ratio (SNR), gain error, $\mathrm{DNL}$, INL, slew rate, input and output range were performed at a sampling rate of $300 \mathrm{MHz}$. For all measurements the DAC system exceeded the requirements for the Modulator as shown in Table 1. References on DAC testing can be found in [4] and [5].

\begin{tabular}{|c|c|c|c|}
\hline Test & Result & Requirement & Units \\
\hline Analog Bandwidth & 64 & $>10$ & $\mathrm{MHz}$ \\
\hline Risetime & 5.5 & $<35$ & $\mathrm{~ns}$ \\
\hline Falltime & 5.5 & $<35$ & $\mathrm{~ns}$ \\
\hline SFDR & 46.8 & $>40$ & $\mathrm{~dB}$ \\
\hline SNR & 60.3 & $>50$ & $\mathrm{~dB}$ \\
\hline Gain Error & 1.4 & $<6.5$ & $\%$ F. S. \\
\hline DNL & \pm 0.3 & \pm 0.5 & $\mathrm{LSB}$ \\
\hline INL & \pm 0.13 & \pm 0.95 & $\mathrm{LSB}$ \\
\hline Slew Rate & 126 & $>23$ & $\mathrm{~V} / \mu \mathrm{S}$ \\
\hline Input Range & 0 to -1000 & 0 to -1000 & $\mathrm{mV}$ \\
\hline Output Range & -12 to -983 & 0 to -1000 & $\mathrm{mV}$ \\
\hline
\end{tabular}

Table 1 -- Table of Test Parameters, Results, and Requirements

\section{OPTICAL POWER CONVERTER SUBSYSTEM (OPC)}

An optically isolated low-voltage power system for each circuit board is used to eliminate ground loops and reduce coupling capacitances. An optical fiber is used to convey laser light to a custom AlGaAs/GaAs solar cell [6] that converts the photonic energy into electrical power for the on-board control circuits. The OPC system has been used in high-voltage transmission line data acquisition systems [7] where isolation of $750 \mathrm{kV}$ is required. The custom photovoltaic cell generates $0.2 \mathrm{~W}$ of peak electrical power from a $1.0 \mathrm{~W}$ laser at a load resistance of approximately 1 $\mathrm{k} \Omega$ as shown in Figure 3.

Power Supplied vs. Load Resistance

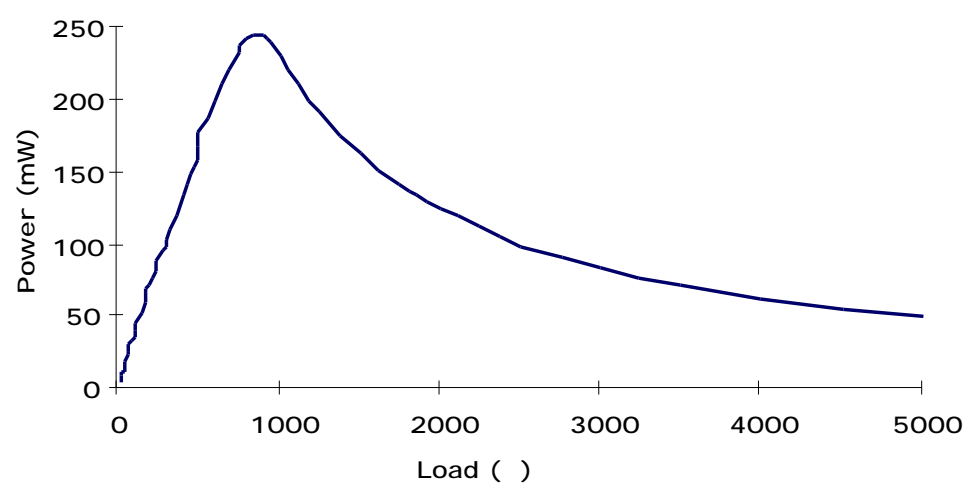

Fig. 3 -- Power Curve for OPC 
The converter was coupled with a voltage regulator to regulate the output voltage to $15 \mathrm{~V}$ for the FET drivers and another regulator was used to step from 15 volts to 5 volts for the optical control receiver. Storage capacitors were used at each regulator stage and the optical receiver to provide additional energy during the switching burst. The circuit was tested on a FET switch board that only switches the FETs ON or OFF, as the analog FET driver circuitry was not available at the time of testing for this paper. Daughter boards with the optical power converter, optical control receiver, and FET drivers were constructed and coupled into a switch board to replace an existing dc-dc converter, control receiver and FET drivers.

For comparison, the same bench setup was used to test both the modified and unmodified switch board. The OPC subsystem was tested for its ability to supply power for long pulses, narrow pulses at high pulse rate frequency and for variable pulse width and frequency. The subsystem was also tested for pulse width distortion, rise/fall time, jitter and droop of the FET gate pulse.

There was no significant difference between the OPC and the original dc-dc converter results for the dynamic tests. The FET switch card draws $4 \mathrm{~mA}$ of quiescent current from the OPC in standby mode and $10 \mathrm{~mA}$ during switching. The optical trigger receiver consumes most of the quiescent current at just over $3 \mathrm{~mA}$. The FET drivers draw $12 \mu \mathrm{A}$ in standby. The short circuit current is rated at $20 \mathrm{~mA}$. Initial charging of the storage capacitors takes $100 \mathrm{~ms}$, allowing the subsystem to be turned on and ready to switch a burst within $500 \mathrm{~ms}$ of turning on the laser to conserve power while the modulator is not switching. The laser has the capability to be modulated from dc to $10 \mathrm{kHz}$. Large scale operation of this subsystem would allow low average power consumption while achieving high power switching. The laser was switched at a rate of $1 \mathrm{kHz}$ and between $30 \%$ and $50 \%$ duty cycle to conserve power during standby. Modulating the laser saves laser lifetime and increases the reliability of the subsystem.

\section{OPTICAL DIAGNOSTIC}

A resistor in series with the source lead of the FETs is used for over-current protection. This resistor has a small value and can be used as a current viewing resistor (CVR). Diagnostic data and status information from each array of FET circuit boards can be measured by converting the voltage across the CVR to light and transmitting through the high-voltage barrier to the control system [8]. A resistor-LED pair is placed in parallel with the CVR, as shown in Figure 4. A small amount of the current flowing through the CVR is diverted through the LED. The resistor in series limits the current through the LED. A plot of output optical power versus current is shown in Figure 5. Fitting a straight line to the data yields a slope of $5.8 \mu \mathrm{W}$ per $\mathrm{mA}$ and $\mathrm{y}$-intercept of $-13.1 \mu \mathrm{W}$.

LED Resistance and Optical Power vs. Current

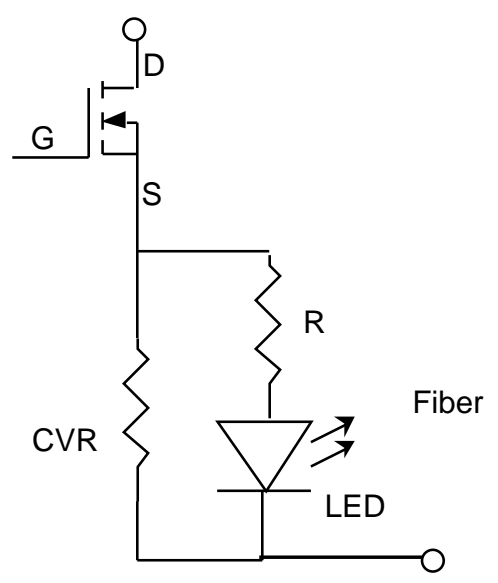

Fig. 4 -- Optical Diagnostic Circuit

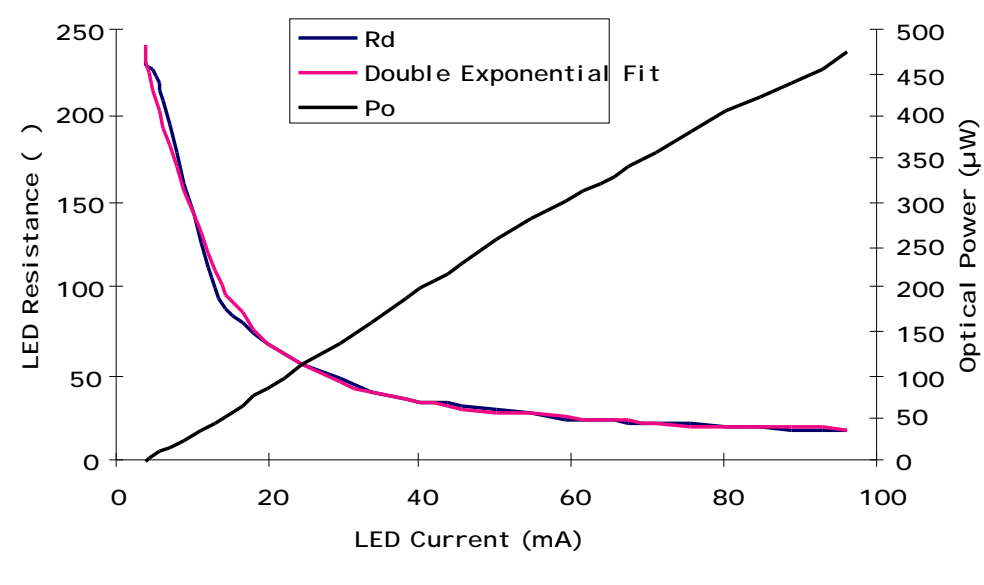

Fig. 5 -- LED Resistance and Power Curves 
A double exponential curve fit of the diode resistance versus current curve (Figure 5) results in equation (1) for $R_{d}$ for values of $i_{d}$.

$$
R_{d}=k_{0}+k_{1} e^{-k_{2}\left(i_{d}\right)}+k_{3} e^{-k_{4}\left(i_{d}\right)}
$$

where: $R_{d}$ is the diode resistance of the LED

$i_{d}$ is the current flowing through the LED

$k_{n}$ is the coefficients of the double exponential fit

A $40 \mathrm{~m} \Omega$ resistor was used as the CVR and a $55 \Omega$ resistor, $R$, was used to limit the current flowing through the LED. The current through the CVR can be calculated from the measured optical power using equation (2) and the straight line fit of $i_{d}$ versus $P_{0}$.

$$
I=\frac{i_{d}\left(R_{d}+R+C V R\right)}{C V R}
$$

where: $R$ is the current limiting resistor

CVR is the current viewing resistor $40 \mathrm{~m} \Omega$

$R_{d}$ from equation (1)

A $4 \mu \mathrm{F}$ capacitor was charged to $500 \mathrm{~V}$ and switched across a load of $10 \Omega$. A plot of the calculated CVR current from the optical power and the actual CVR current is shown in Figure 6. Lowering the value of $\mathrm{R}$ will divert more current to the LED and increase the sensitivity at lower

CVR current.

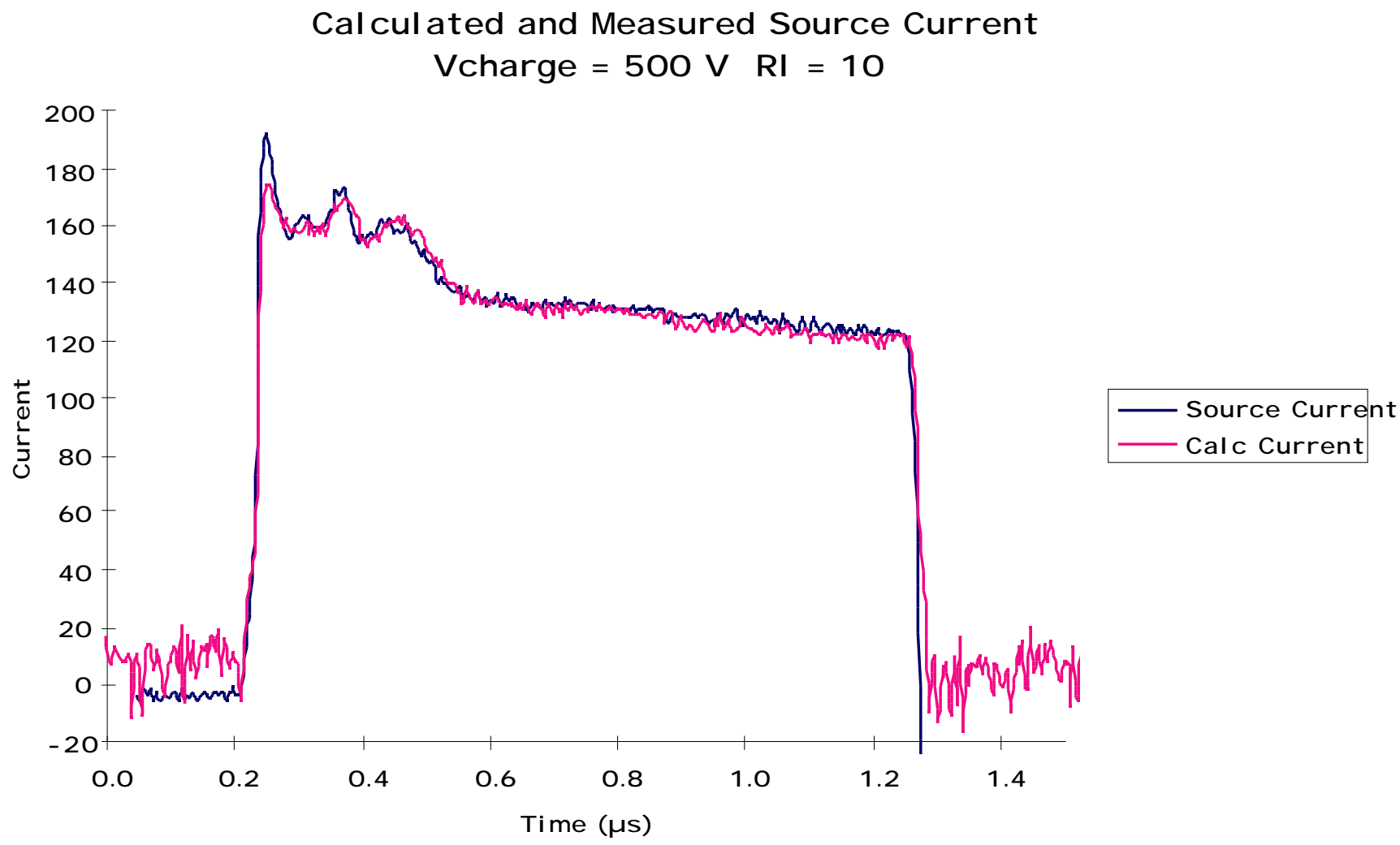

Fig. 6 -- Measured and Calculated Source Current 


\section{CONCLUSION}

VCSEL transceiver links and digital-to-analog converters can be used to transmit analog signals through optical fibers for high-voltage isolated systems. The creation of digital word waveform is easily accomplished with commercially available generators and transmission of this waveform through optical fiber is an effective medium. Conversion from a digital waveform can be accomplished with standard DACs. Future systems will utilize the digital output from an arbitrary waveform generator to avoid the process of converting from analog to digital by starting in the digital domain.

A method of supplying electrical power to high-voltage isolated systems utilizing laser energy delivered to a photovoltaic cell via optical fiber has been demonstrated. The system has been designed to allow conservation of energy and laser lifetime by switching the laser on just prior to triggering the modulator, then switching off the laser. Further conservation can be accomplished by modulating the laser during the operation of the solid state induction modulator. Diagnostic signals can be transmitted through a high-voltage isolation barrier with optical fibers. Tapping the current flowing through the source lead of the FET with a CVR for the drive current of a LED is used for a voltage isolated diagnostic of the current switched by the FET.

\section{References:}

[1] H. Kirbie, et al., "Development of Solid-State Induction Modulators for High PRF Accelerators," Tenth IEEE International Pulsed Power Conference, 1995, pp. 1061-1022.

[2] R. A. Nordin, W. R. Holland, and M. A. Shahid, "Advanced Optical Interconnection Technology in Switching Equipment," Journal of Lightwave Technology, Vol. 13, June 1995, pp. 987-994.

[3] Y. Wong, et al., "Technology Development of a High-Density 32-Channel 16-Gb/s Optical Data Link For Optical Interconnection Applications for the Optoelectronic Technology Consortium (OETC)," Journal of Lightwave Technology, Vol. 13, June 1995, pp. 995-1016.

[4] “Understanding Data Converters”, Texas Instruments, SLAA013, July 1995.

[5] N. Cravotta, "Electronic Palindromes: Converting A/D-D/A," in Communication Systems Design, July 1996.

[6] K. R. Wickham, B-C. Chung, M. S. Kuryla, M. Ladle Ristow, G. F. Virshup and J. G. Werthen, "Recent Advancements in Monolithic AIGaAs/GaAs Solar Cells for Space Applications," in Space Photovoltaic research and Technology, (NASA Conference Publication 1991).

[7] J. G. Werthen, M. Ladle Ristow and K. R. Wickham, "An Optically Powered Data Link," in Conference Record of Opto 93, ESI, Paris 1993, pp. 75-77.

[8] G. L. Brendenkamp, J. J. Nel, D. J. Mulder, "Transient Voltage Sharing in Series Coupled High Voltage Switches“, Pulsed Power Conference, 1991, pp. 1016-1019.

Work supported by the U. S. Department of Energy Nevada Operations Office under Contract No. DE-AC08-96NV11718.

By acceptance of this article, the publisher and/or recipient acknowledges the U. S. Government's right to retain a nonexclusive, royalty-free license in and to any copyright covering the article.

*This work was performed under the auspices of the U.S. Department of Energy by the Lawrence Livermore National Laboratory under Contract No.W-7405-Eng-48. 


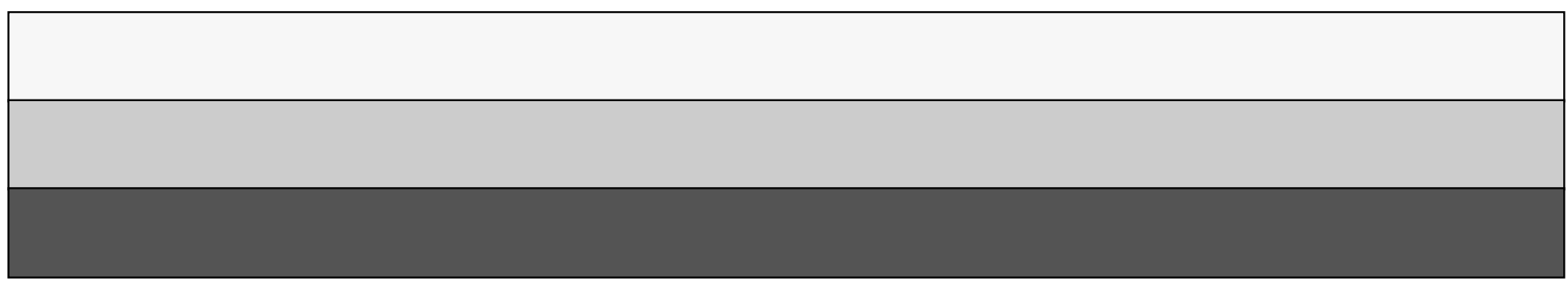

